\title{
Andrea Schellino, "Je suis un des premiers qui l'ont compris». Sur la prétendue «rencontre manquée» de Baudelaire et Manet
}

\section{Mario Richter}

\section{(2) OpenEdition \\ Journals}

Edizione digitale

URL: http://journals.openedition.org/studifrancesi/4435

DOI: $10.4000 /$ studifrancesi.4435

ISSN: 2421-5856

\section{Editore}

Rosenberg \& Sellier

\section{Edizione cartacea}

Data di pubblicazione: 1 settembre 2016

Paginazione: 355

ISSN: 0039-2944

\section{Notizia bibliografica digitale}

Mario Richter, "Andrea Schellino, "Je suis un des premiers qui l'ont compris». Sur la prétendue "rencontre manquée» de Baudelaire et Manet », Studi Francesi [Online], 179 (LX | II) | 2016, online dal 01 septembre 2016, consultato il 17 septembre 2020. URL : http://journals.openedition.org/studifrancesi/4435 ;

DOI : https://doi.org/10.4000/studifrancesi.4435

\section{Questo documento è stato generato automaticamente il 17 settembre 2020.}

\section{cc) (†) $\odot$}

Studi Francesi è distribuita con Licenza Creative Commons Attribuzione - Non commerciale - Non opere derivate 4.0 Internazionale. 


\title{
Andrea Schellino, «Je suis un des premiers qui l'ont compris». Sur la prétendue «rencontre manquée» de Baudelaire et Manet
}

\author{
Mario Richter
}

\section{NOTIZIA}

ANDREA SCHELLINO, «Je suis un des premiers qui l'ont compris». Sur la prétendue «rencontre manquée» de Baudelaire et Manet, «Romanistische Zeitscheift für Literaturgeschichte / Cahiers d'Histoire des Littératures Romanes» 39, 3/4, 2015, pp. 347-355.

L'articolo si presenta come un approfondimento e una contestazione delle pagine che Wolfgang Drost, riconosciuto specialista dell'argomento, ha precedentemente pubblicato nella stessa rivista $(1 / 2,2014)$ col titolo «Vous n'êtes que le premier dans la décrépitude de votre art». Baudelaire et Gautier, Zola et Mallarmé devant la modernité de Manet. Il problema da risolvere sta essenzialmente nella reticenza che, secondo Drost, Baudelaire avrebbe manifestato nella valutazione dell'arte di Manet. Schellino articola il suo intervento in cinque punti, nell'intento di sottolineare la ricostruzione «conjecturale et fragile» del pur documentato studio di Drost tendente a mettere in luce un atteggiamento reticente e ingiusto di Baudelaire nei riguardi del suo amico pittore Manet. In primo luogo l'A. mira a dimostrare che la quartina dedicata da Baudelaire al quadro Lola de Valence, «à la différence de ce que Wolfgang Drost écrit, [...] est bien un signe d'admiration, d'affinité et d'amitié». Quanto all'assenza di Manet nell'articolo baudelairiano dedicato a Constantin Guys (Le Peintre de la vie moderne), l'A. tende a giustificarla, scostandosi dalla valutazione di Drost, considerando che l'articolo non è un riassunto dell'arte dell'epoca, bensì di un suo aspetto collegabile ad artisti come Daumier, Gavarni, Devéria e ad altri sensibili a un particolare genere di "modernità". Relativamente all'interpretazione di Drost circa la frase scritta da 
Baudelaire in una lettera a Manet dell'11 maggio 1865 («Vous n'êtes que le premier dans la décrépitude de votre art»), interpretazione secondo cui Manet sarebbe posto a capo («le premier») del movimento dei novatori che sarebbero però considerati da Baudelaire in termini negativi («la décrépitude de votre art»), nell'ampia conclusiva parte dell'articolo Schellino tende a sostenere che la «décrépitude» attribuita da Drost all'arte di Manet sarebbe in realtà da riferirsi soltanto a quella di un «monde épuisé» nel quale Manet appare essere «un esprit supérieur». Ciò consente all'autore di concludere, discostandosi dal giudizio di Drost, che «malgré sa solitude existentielle et artistique, Baudelaire, au-delà de leur amitié, au-delà de son attachement à l'art de Delacroix, a compris Manet dès le début». 